\title{
Forecasting Technology Trends through the Gap Between Science and Technology: The ase of Software as an E-Commerce Service
}

\author{
Tugrul Daim \\ Professora; Guest Researcherb, tugrul.u.daim@pdx.edu \\ Esraa Bukhari \\ PhD Studenta ${ }^{\mathrm{a}}$, ebukhari@pdx.edu \\ Dana Bakry \\ PhD Student ${ }^{\mathrm{a}}$,dbakry@pdx.edu \\ James VanHuis \\ PhD Student ${ }^{\mathrm{a}}$, jvanhuis@pdx.edu \\ Haydar Yalcin \\ Associate Professorc , haydar.yalcin@gmail.com
}

Xiaoli Wang

PhD Student ${ }^{\mathrm{d}}$, bjutwxl@qq.com

a Portland State University, 1900 SW 4th, Portland OR 97201 USA

b Institute for Statistical Studies and Economics of Knowledge (ISSEK), National Research University Higher School of Economics, 11, Myasnitskaya str., Moscow 101000, Russian Federation

c Division of Management Information Systems, Department of Business Administration Faculty of Economics and Administrative Sciences Ege University, Erzene Mahallesi Ege Üniversitesi Merkez Yerleşkesi, 35040 Bornova/İzmir, Turkiye

${ }^{\mathrm{d}}$ Beijing University of Technology, NO.100, Pingle Garden,Chaoyang District, Beijing City, China

\begin{abstract}
I dentifying technology trends can be a key success factor for companies to be competitive and take advantage of technological trends before they occur. The companies always work to plan for future products and services. For that, it is important to turn to methods that are used for technology forecasting. These tools help the companies to define potential markets for innovative new products and services. This paper uses text mining techniques along with expert judgment to detect and analyze the near-term technology evolution trends in a Software as a Service (SaaS) case study. The longer-term technology development trend in this case is forecasted by analyzing the gaps between science and technology. This paper contributes to the technology forecasting methodology

and will be of interest to those working with SaaS technology. Our findings reveal five trends in the technology: 1) virtual networking, 2) the hybrid cloud, 3) modeling methodologies, 4) mobile applications, and 5) web applications. Among the results achieved, we can summarize the interesting ones as follows: it is possible to say that traditional information systems are now evolving into online information systems. On the other hand, the use of a licensing model based on subscriptions triggers the change in perpetual licensing models. The product range that has evolved toward mobile technologies has put pressure on information storage technologies and has led to the search for new methods especially in the development of database systems.
\end{abstract}

Keywords: technology trends; technology forecasting; technological trajectory; text mining; e-commerce; software as a service; SaaS; patent citation

Citation: Daim T., Bukhari E., Bakry D., VanHuis J., Yalcin H., Wang X. (2021) Forecasting Technology Trends through the Gap Between Science and Technology: The Case of Software as an E-Commerce Service. Foresight and STI Governance, 15(2), 12-24. DOI: $10.17323 / 2500-2597.2021 .2 .12 .24$ 
$\mathrm{F}$ orecasting the trend of technologies creates potential opportunities for companies in the industry and for governments to engage in international competition. The business world is dynamic. Companies always work to plan for future products and services. For that, it is important to turn to methods that are used for technology forecasting. These tools help the companies define potential markets for innovative new products and services. In recent years, it has been shown in different research and development projects that patents and scientific papers contain considerable amounts of important information about developed technologies [Kim, Bae, 2017]. Identifying technological trends and acting upon them can give enterprises and countries a strategic edge which results in more progression in society and an advantage in global competition [Li et al., 2019]. Most critical decision makers are aware of the importance of being ahead of competitors in detecting and taking advantage of technological trends particularly in our current knowledge economies. Therefore, if organizations, either profit or nonprofit, want to gain sustainable competitive advantages, they need to move early in identifying emerging technologies and pursue the continuous process of innovation which will result in their competitiveness and development. So, in following this approach as a strategic issue one should ask how we can identify technological trends ahead of competitors and forecast the next stages of emerging technologies to create more wealth for society. This is not only important for identifying technological trends but also shows the probable pathways for disruptive technologies. In order to answer the question concerning the identification and forecasting of technological pathways, this paper provides a framework and uses SaaS technologies as a case so that we can understand the evolutionary growth of a technology and possible future states.

The aim of this study is to apply text mining and citation analysis of scientific papers and published patents in software as a service or SaaS technology to reveal the technology trends in this industry and apply it as a technology forecasting approach. The method used in this paper can be applied by industry, government, and academia to develop technology investment and development plans.

\section{Literature Review}

As the computational capacity and abundance of data and information have been increasing in this era of big data and artificial intelligence, scientific research has access to powerful tools that dig deeper into the fruitful sources of data to understand the future scenarios of scientific and technological trends. Scientific papers and patents are important containers of information about technologies that can be exploited using novel techniques in order to understand emerging patterns of technological trends. Some methods like text mining and patent analysis allow researchers to investigate technological documents and mine for useful information in a systematic way [Madani, Weber, 2016]. Therefore, patents and scientific papers have been widely used as a source of data in revealing the technological trends and their consequences [Ghazinoory et al., 2013; Huang et al., 2018; Kim, Bae, 2017; Madani, Weber, 2016; Park, Yong, 2017; Wang et al., 2015; Yoon et al., 2014]. In fact, technological forecasting has been mostly developed by applying qualitative methods which today are often complemented by quantitative approaches. As more powerful computational tools allow, citation analysis, co-word analysis, patent analysis, topic analysis, bibliometric analysis, and text mining have become popular among a diverse range of avail- able methods in technology forecasting. The appearance of the software-as-a-service ( $\mathrm{SaaS}$ ) business model has attracted big observations from both researchers and practitioners [Ma, 2007] and the determination of the future potential of Software-as-a-Service for company applications is considered a pivotal input for software companies' strategy growth [Cusumano, 2008]. The integration is a necessity in SaaS adoptions since SaaS contains business data and logics [Elfatatry et al., 2002]. For that, forecasting technology helps to assist the SaaS integration life cycle.

\section{Text Mining}

Text mining is one of the emerging techniques in analyzing technological trends and forecasting. It can empower researchers to assess and visualize technical information and patterns in scientific papers and patent documents [Madani, Weber, 2016]. Basically what text mining does on these technical documents is mining and finding bucketed constructs of words with the highest frequency and importance so as to focus on the deeper meaning that can be captured from this contextual information [Rezaeian et al., 2017]. Analyzing the characteristic features of extracted patterns over time brings a larger picture to the surface in identifying technological trends and pathways. Many scholars have been applying text mining methods to show the relationships among different keywords, citation referrals, and co-occurrence of words to extract and visualize technological trends and their technical associations which can be applied in the technology planning phase [Boyack et al., 2018; Ghazinoory et al., 2013; Huang et al., 2018; Rezaeian et al., 2017; Yoon et al., 2014].

Although fitting text mining models can provide an approximation about the schemas in a technical area, the trend of the detailed content is not easily illustrated. It is difficult to decipher the association between keywords and specific topics. In fact, the temporal patterns of keywords do not necessarily demonstrate the topic of a technological concept [Chen et al., 2017]. Therefore, the extraction of meaning from the results of pure text mining upon only keyword analysis can be very difficult.

\section{Citation Analysis}

Citation analysis generally refers to the insights that come from the knowledge relationships between a network or cluster of papers and patents in specific area of knowledge. So, it has been extensively used to reveal the trends surrounding technological innovations [Garcia-Lillo et al., 2016; Kostantinos, 2019; Angelou et al., 2019; García-Lillo et al., 2019; Teufel et al., 2009].

Citation analysis reveals the hidden relationships and structural properties in scientific papers and patents that demonstrate the commonalities of knowledge flows that share specific connections. Through applying this approach in digging deeper into the clusters of papers and patents related to the path of technological trends and new developments, valuable evolutionary patterns of technological moves can be identified. Scholars have extensively applied citation analysis to study technology development trends [Angelou et al., 2019; Boyack et al., 2018; Hasner et al., 2019; Kim et al., 2016; Kose, Sakata, 2018]. For instance, Boyack et al. did a large-scale analysis of in-text citation that revealed the higher-level scientific relationships between multiple research areas which would be beneficial in structuring research questions. Such an assessment would probably be efficient in identifying technological convergence which emerges from seemingly unrelated areas of science and technology [Boyack et al., 2018]. 
Scientific papers and technological patents are invaluable sources of technological knowledge which can be exploited and mined using the available computational tools. However, some scholars assume that just concentrating on citation analysis would not be comprehensive [Madani, Weber, 2016]. Novel data science techniques, statistical learning methods, and computational tools can highly improve the level of analysis that scholars do using text mining, which delves into the detailed knowledge contained in multiple technological developments and trends. Analyzing the fundamental characteristics of words and their frequency in the documents can potentially show the deeper meaning behind these relationships. But one drawback of such keyword mining in co-word assessment is the concept of meaning which arises from such connections. Text mining methods that solely rely on the counting of words and their frequencies would frequently miss the important part of the concept which can be elucidated by human expertise.

\section{Technology Forecasting}

Technology forecasting is a class of systematic methods that demonstrates the expectations of the future direction, rate of change, and the properties of technological pathways. Scholars have widely used a very diverse set of technology forecasting techniques in different technological domains to better understand the evolutionary paths of technological trends [Coates et al., 2001].

For example, one of the seminal and groundbreaking studies is Christensen's concept of disruptive technologies [Christensen, 2000]. The main cornerstone in such research is the concept of the S-curve in tracking the technological trends. The S-curve has been a very useful and simple approach in realizing the differences of sustainable and disruptive technologies. Essentially, technology forecasting is not purely quantitative or qualitative in nature so that, for instance, we come up with a specific quantity and try to apply interpolation.

In the literature there are different types of approaches used in technology forecasting. Lee et al recommended a method relying on the Hidden Markov Model in grouping technologies in the IT sector and present evolutionary patterns [Lee et al., 2011]. Bangisu and Nekhili studied emerging technologies based on a technology forecasting technique which is about analyzing papers and patents. They found a strong correlation between the number of papers and patent data [Bengisu, Nekhili, 2006].

There are couple of other methods used in technology forecasting which namely are the S-curve, the adoption curve, text analysis, and so on. This wide range of technology forecasting methods applied in different contexts show that this area of knowledge is very broad and scholars have taken advantage of this diverse spectrum.

\section{Methodology}

Text mining is one of the most frequently used methods to follow the change in technology based on experimental data. Text mining for technology management is called technology mining [Porter, Cunningham, 2004]. In our study, the technology mining method was used together with bibliometric, sciencemetric, and social network analysis techniques. As a dataset, international scientific publications in Web of Science (WOS) and patent data indexed in Derwent Innovation Index are handled together. Based on the data obtained, inferences were made on the use of software as a service in the electronic commerce sector. For this purpose, the term "Software as a
Service" and "E-Commerce" and "SaaS" are used in the terms of query. The bibliographic data obtained in order to clear the publications that should not be included in the study were reviewed. Obtaining the clustered topics is only one part of the forecasting framework used in this paper. Following the work done by [Li et al., 2019], we utilized a six-step process to identify the gaps in science and technology and forecast the future trends of the technology.

Step 1. Data Collection. We utilized the Web of Science (WOS) database for the scientific articles and the Derwent Innovation Index (DII) database to collect the patent information. The query was conducted using the keywords "Software as a Service" and "E-Commerce" as well as the abbreviation "SaaS".

Step 2. Preprocessing the data. The articles from the WOS results had to be cleaned extensively since the Zermatt-SaaS zone is a tectonic unit in the Western Alps and appeared frequently in our searches. Once excluded for geological and other non-software results, we further separated the articles into year published for analysis. The patent information was retrieved and cleared in a similar fashion and separated by year.

Step 3. Various social network theories were used in cluster analysis. In this context, it is preferred to apply a minimum spanning tree frequently in clustering concepts. The minimum spanning tree gives the shortest path around all the nodes in a weighted graph (i.e., the cost (weight) of the paths connecting each node) [Graham et al., 1985]. The Pathfinder algorithm is used to differentiate the clusters where the number of connections is much higher depending on the size of the dataset, thus, it is possible to identify structures consisting of more than one minimum spanning tree [Chen, 1998]. CiteSpace software was used to create clusters and calculate the basic social network metrics [Chen et al., 2010].

Step 4. Creating the Hierarchical Structure methodology for the technology. The hierarchical structure was developed with the assistance of an expert in SaaS, who inspected the results of the technological clustering of topics and labeled them into three categories based upon their knowledge and experience.

Step 5. Constructing the Evolution Maps methodology for the technology. Technology evolution maps are used to identify dominant technology areas [Rongying et al., 2010]. The technical topic clusters along with the developed hierarchical structure were used to construct technology evolution maps. The differences and gaps in the two evolution maps are then used in step 6 to forecast the technological trend.

Step 6. Forecasting the Technological Trend methodology. The gaps in technical knowledge between the scientific papers and the patents were used to forecast the trend. Comparing the differences in appearance of technical topics and their rate of growth led us to forecast the future trend. See Figure 3.

\section{Case Study}

SThis case study focuses on software as a service (SaaS) technology in the papers and patent dataset and text mining was used to help discern trends. SaaS technology is a type of cloud computing service technology model, centrally hosted and licensed software on subscription basis [Laplante et al., 2008]. In 2001, SaaS first appeared in a Strategic Backgrounder article: Software as a Service, by the Software \& Information Industry Association [SIIA, 2001] eBusiness Division. SIIA expected a potential change of software applications filed for personal use, collaborative, and enterprise. And, it was beneficial to reduce time, lower cost, and create a scalable prod- 
uct that was also integrable with another SaaS, easy to use, and highly developed [Chen et al., 2011]. SaaS was selected as a case for this study due to its scientific and technological importance and impact. Therefore, forecasting technology trends from the gap between science and technology of SaaS will significantly assist personal users, managers, policymakers, and developers.

\section{Data Collection}

On February 20, 2019, the authors used the Web of Science (WOS) as a research paper database and Derwent Innovations Index (DII) for patents. The term "(Software as a service) OR (SaaS) AND (e-commerce)" was used as the request to explore WOS to find 2,784 papers on the topic from secondary sources from the year 2014 until 2018. The term "(Software as a service) OR (SaaS) AND (e-commerce)" was selected as the request to explore DII to find patents in the database, and 869 issued patents were found from the year 2014 until 2018.

Figure 1 shows the scientific papers and patents related to SaaS technology data selected between 2014 and 2018, and it can be seen that the number of scientific papers and patents increased slightly between 2014 and 2017. The blue line shows the growth in scientific papers from 126 to 147 during the period from 2014 to 2015 . The highest rate of growth for scientific paper publications during our review period was 147 papers in 2015. The red line shows the growth in scientific patents from 37 to 69 during the period from 2015 to 2017. Interestingly, the number of patents was highest at 86 patents in 2014, the first year of our review.

\section{Topic Clustering}

Scientific papers and patents were processed together for every year. They include the keywords that contain "SaaS" and "Software as a service", "Adoption", "Iot", "Qos", and "Game Theory" in the title. The data were saved in plain text format to be processed with Citespace software. We used Pathfinder network scaling to reduce the number of links. With this method we can show the most salient links after the pruning process and subsequent expert validation of the results (expert profiles can be seen in Table 1). After processing this data and reviewing the clustering topics, authors selected up to $50 \%$ of the common key terms based on the repetition numbers of the articles that have the selected topic and removed non-relevant topics. Then, the experts focused on e-commerce SaaS technology studies. Experts aided in clustering the results of our topics of research based on their domain knowledge. We obtained topics based on scientific papers and patents for every year along with the expert consultations. The annual extraction results are shown with their represented number of topics in Table 2 and Table 3.

\section{Hierarchical Structure of Technology Generation}

A hierarchical structure is a diagram that represents the relationships among technologies based upon each division and subdivision [Choi et al., 2012]. The technological picture represents the connections between product/service components, technologies, or specific technological functions [Bildosola et al., 2017; Choi et al., 2012]. The hierarchical structure of technology generation can be utilized as an in-depth analysis of the technology area selection [Yoon, Park, 2005]. This paper has set it out to understand the technological evolution of SaaS technology. It is important to build the hierarchical structure of technology generation to provide the classifications for the topic clustering results. The purpose of doing this for SaaS is to gain an overall methodological understanding of the evolutionary path, determine the gap between scientific papers and patents, and forecast the technological trends for this technology. As mentioned in the methodology section, our cluster topics are treated as objective evidence to make decisions. To find the cluster results from the topic analysis, we combined quantitative and qualitative methods and built the SaaS hierarchical structure. Therefore, our two domain experts engaged in the classification of SaaS topics. First, the experts divided the topics into three categories according to their knowledge and experience and classified each label into a sub-division. The three categories also fully reflect the personal users, managers, policymakers, and developers' directions for the SaaS technology. The following three categories of SaaS technology are considered: "Package software", "Operation system application stack", and "Other; server, storage, network, security, and usability". The "Package software" category addresses the server, data, and code used in SaaS package software technology. The "Operation system application stack" addresses the server, data, and code used in SaaS operation system applications. Finally, the "Other; server, storage, network, security, and usability" is related to the technology keys used in SaaS technology. The result of this information can classify the topic clustering results and generate an evolutionary map to define the technological trends. According to the three selected categories, the experts merged relevant technological topics while each parallel category and layer have mutual functions and characteristics that are related to the technology of SaaS. As shown in Figure 2, the hierarchical structure of the SaaS technology was constructed.

The trend of forecasting technological development is an outcome of defining the path of the technological evolution. The results of topic clustering in the short term are important to understanding the evolutionary path of the software as a service technology. Also, it helps to forecast its development trends for the same period. The map of the technological evolution was constructed based on the scientific papers and another based on the patents. In this case study, our clustering topic results are obtained from scientific papers and patents database from 2014 to 2018 to fully understand the technical topics, which we use to build the evolutionary map of SaaS technology. Firstly, our domain experts categorize the topics in Table 2 and Table 3 that are shown as the hierarchical structure of the technology. The division and sub-division categorizations are shown in Table 4 . Then, the evolutionary map of SaaS technology is generated according to the result of clustering the topics from the databases. Lastly, the trend

\section{Figure 1. Statistical results of scientific papers} and patents related to SaaS technology

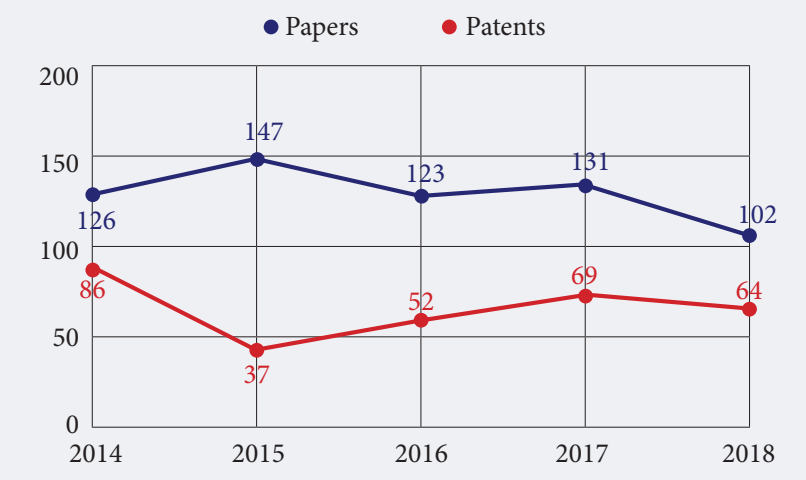

Source: compiled by the authors. 


\section{Table 1. Domain Expert Profiles}

\begin{tabular}{|l|l|l|}
\hline No. & \multicolumn{1}{|c|}{ Affiliation } & \multicolumn{1}{c|}{ Background } \\
\hline 1 & $\begin{array}{l}\text { DePaul } \\
\text { University, US }\end{array}$ & $\begin{array}{l}\text { Focused on e-commerce studies for } \\
\text { more than 10 years, and working as } \\
\text { an e-commerce assistant manager in } \\
\text { Saudi Airline Catering }\end{array}$ \\
\hline 2 & $\begin{array}{l}\text { Long-Island } \\
\text { University, US }\end{array}$ & $\begin{array}{l}\text { Has experience in programming, } \\
\text { banking, networking, technical } \\
\text { documentation, data report } \\
\text { compilation, e-commerce, and } \\
\text { e-payment platforms }\end{array}$ \\
\hline
\end{tabular}

of SaaS technology development was examined through the gaps found in the scientific and patent databases based on the created map of technological evolution.

\section{Analysis of the Technology's Evolutionary Path Based on Scientific Papers}

Our two domain experts with the help of two senior researchers have selected the technical topics of the scientific papers based on the categorization of clustering results from the period of 2014 to 2018, as shown in Table 5. Table 5 represents the technical topics' appearance year. The number between the brackets represents the number of documents containing the topic. In Table 4, the obtained technical topics in the scientific papers related to SaaS technology in 2014 includes; Cloud Computing, Multi-Tenancy, Reference architecture, Feature Modeling, High Performance Computing, Software Recommendation, Virtual Machine, Radio frequency identification, Digital Campus, Web Application, semantic web, Cloud Service, Storage, Network, and Wireless sensor network. In 2015, many new technical topics appeared for the first time, such as Quality, Multi-Layer Fuzzy Cognitive Maps, Video Mixing, Genetic Algorithms, Hill Climbing, Social Software, Web Service, Service Discovery, Security, Identity Management, and Adoption. In 2016, the technical topics that appeared are Data Isolation, Dynamic Quality Attributes, Learning Automata, Cloud Library Service, and Technology Acceptance Model. In 2017, the following technical topics that appeared are Dynamic Data, Virtual Network Embedding, Hybrid Cloud, Attribute Based Access Control, Privacy Protection and Resource Sharing. In 2018, there are a few new technical topics that appeared. They include SaaS Placement, Modeling Methodologies, Network Effect, and Cloud Tech.
The development of the new technical topics shows that the basic research on SaaS is related to Package Software, the Operation System Application stack and other topics including Server, Storage, Network, and Security. Also, it shows that the basic research development of the technology is slightly increasing.

In Table 5, the technical topics of scientific papers on SaaS between 2014 and 2018 are presented. This table shows that the software package demonstrated a high growth rate in 2014. The operation system application stack showed a high growth percentage in 2015. Security demonstrated high growth in 2017. Overall, the highest rate of scientific paper technical topics appeared in 2015. Forecasting the future development potential of the technology relies on their high growth rate [Bildosola et al., 2017]. Scientific papers that have high growth rates show that those on package software, the operation system application stack, server, network, security, storage, and usability have great development potential. Mobile applications and web applications will be future research focuses of software as a service technology.

The authors generated the evolutionary map based on the clustering results that have been selected from the scientific database and experts' experience in order to understand the detailed evolutionary path of software as a service technology. Our two domain experts generated the map of the technology's evolution according to its hierarchical structure and the annual technical topics shown in Table 5. We categorized topics into appropriate layers of SaaS and located them on the evolutionary map based on scientific papers in Table 5 . As shown in Table 5, the vertical axis represents the Package Software layer, Operation System Application stack layer, and others include the "Server, Storage, Network, Security and Usability" layer of the software as a service technology obtained from the hierarchical structure's first layer. The horizontal axis represents year. By analyzing the variation of elements in each layer over time, we are able to understand the development process of SaaS technology.

It is clear that there has been a change in the debates on information technologies in scientific publications between 20142018. It was observed that technologies evolving from traditional information systems to online and mobile information systems and accordingly, information storage methods are in high demand. Information security is also among the other topics that are concentrated upon (Table 5). In the package software layer, there are many technical topics in scientific pa-

Table 2. Obtained Results of the Topics Extracted from Scientific Papers

\begin{tabular}{|c|l|}
\hline $\begin{array}{c}\text { Year of } \\
\text { publication }\end{array}$ & \multicolumn{1}{c|}{ Topic (number of publications) } \\
\hline 2014 & $\begin{array}{l}\text { Multi-tenant SaaS (27); SaaS Security (26); Cloud Computing Technology Application (22); Enterprise Systems (16); } \\
\text { SaaS Pricing (11); Engineering Approach (10); Number of Companies (4); Relational Tables (4); Service Request } \\
\text { Scheduling (4); Automated Testing (2). }\end{array}$ \\
\hline 2015 & $\begin{array}{l}\text { Infrastructure as a Service IaaS Providers (22); SaaS Web Service (22); Multi-tenant SaaS (20); Component Services (17); } \\
\text { SaaS Testing (17); Business Processes (13); Mobile Network (11); Security Challenges (11); Big SaaS (9); SaaS ERP (5). }\end{array}$ \\
\hline 2016 & $\begin{array}{l}\text { Cloud solutions (34); Design and Development (23); Business Processes (19); Data Storage (18); Factors for Adopting } \\
\text { (11); Allocate Resource (6); SLA Violations (5); Sentimental Analysis (3); Retrieving Images (2); Security Testing and } \\
\text { Performance Testing (2). }\end{array}$ \\
\hline 2017 & $\begin{array}{l}\text { Secure Service (23); Algorithm for SaaS (18); SaaS Companies (18); Multi-tenant Service (15); Software Testing (15); } \\
\text { System Performance (15); Applications need to be Tested (14); Services Composition (6); Quality Attributes (4); } \\
\text { Education Institution (3). }\end{array}$ \\
\hline 2018 & $\begin{array}{l}\text { Service Selection (8); Course (5); Customization Strategies (4); Composite SaaS Placement (3); Image (3); Data Analysis } \\
\text { Workflows (2); ERP Software (2); ERP Software (2); Tenant Isolation (2); E-Learning (2); SLA Violations (2). }\end{array}$ \\
\hline Source: compiled by the authors.
\end{tabular}



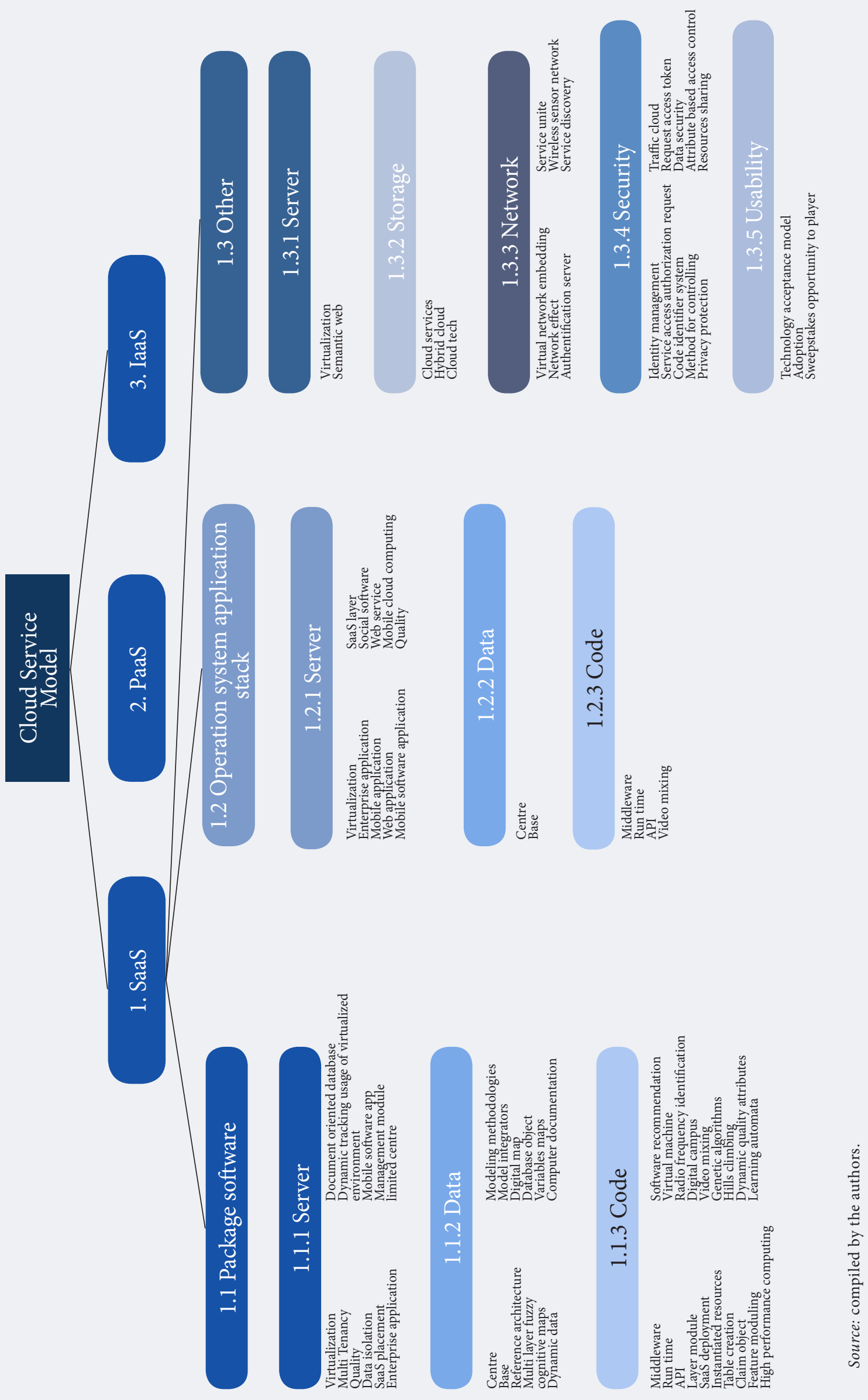


\section{Table 3. Obtained Results of the Topics Extracted from Patents}

\begin{tabular}{|c|l|}
\hline $\begin{array}{c}\text { Year of } \\
\text { publication }\end{array}$ & \multicolumn{1}{c|}{ Topic (number of patents) } \\
\hline 2014 & $\begin{array}{l}\text { Cloud Infrastructure System (14); Managed Mobile Application (13); Tenant of Tenants (13); SaaS Usage (11); Cloud } \\
\text { Monitoring (10); Information Indicative (10); Module Integrator (6); Particular Device (5); Hardware Layer (2); Table } \\
\text { Creation (2) }\end{array}$ \\
\hline 2015 & $\begin{array}{l}\text { Mobile Application (8); Application Instance (6); Instantiated Resources (5); Service Account (5); Client Node (3); } \\
\text { Group Transaction (2);Map Viewport (2); Patent Database (2); Requested Content (2); Sweepstakes Opportunity to } \\
\text { Player (2) }\end{array}$ \\
\hline 2016 & $\begin{array}{l}\text { Enterprise Computing Environment (8); Management Module (8); Authorizing Access to a Service (7); Business } \\
\text { Resource (6); Method for Integrating (6); Code Identifier System (3); Instructions for Navigating (3); Code Analysis } \\
\text { System (2);Dynamically Tracking Usage of Virtualized Environment (2) }\end{array}$ \\
\hline 2017 & $\begin{array}{l}\text { Management Module (18); SaaS Virtual (15); Mobile Software Applications (9); Operating State (7); Client Terminal } \\
\text { (6); Traffic Cloud (5); Database Object (3); Digital Map (2) Oil Carrier (2); Variable Term (2) }\end{array}$ \\
\hline 2018 & $\begin{array}{l}\text { Authentication Server (11); Service Unit (10); SaaS Layer (9); Management Module (8); Computer Documentation (7); } \\
\text { Access Token (6); Secure Machine Environment (4); Shared Key (4); Set of Objects (3); Account Number (2) }\end{array}$ \\
\hline Source: compiled by the authors. \\
\hline
\end{tabular}

pers related to SaaS technology such as: Multi-Tenancy, Reference Architecture, Feature Modeling, High Performance Computing, Software Recommendation, Virtual Machine, Radio Frequency Identification, and Digital Campus have appeared with changes over time, which shows that cloud computing gradually changed from 2014 to 2015 . The first layer of the SaaS "Software package" includes server, data, and code. The "server of software package" includes multitenancy technology which appeared in 2014 and increased by 2017 , quality in 2015, and data isolation in 2016. In SaaS "operation systems and application stack" there is server, data, and code. The "server of operation systems and application stack" includes web applications that appeared in both 2014 and 2015, web services in both 2015 and 2018, quality in 2015, mobile cloud computing 2015, and social software in 2015. In the "code of operation systems and application stack", video mixing appeared in 2015. In the "operation systems and application stack" there was a development in the web application technology and web service technology regardless of the gap in the development of scientific papers on the subject be- tween 2016 and 2017. The third division of the first layer of SaaS "Other" includes server, storage, network, and security. In scientific papers on the "SaaS server", the semantic web was the only technical topic to appear in 2014. In scientific papers on "SaaS storage", cloud services appeared in both 2014 and 2016, storage appeared in 2014 and 2017, hybrid cloud in 2017, and cloud tech in 2018. In the scientific paper on "SaaS network", the term network appeared in 2014, wireless sensor network in 2014, service discovery in 2015, virtual network in 2017, and network effect in 2018. In the scientific papers on "SaaS security", security first appeared in between 2015 and 2018 , identifying management in 2015, attribute-based access control in 2017, privacy protection in 2017, resource sharing in 2017, and SaaS placement technology in 2016. In the data on software packages, reference architecture appeared in both 2014 and 2015, multi-layer fuzzy cognitive maps in 2015, dynamic data in 2017, and modeling methodologies in 2018. In "code of software package", the virtual machine appeared in 2014,2015 , and 2016, feature modeling in 2014, high performance computing in 2014, software recommendation in 2014,

Table 4. Classification of the Topic Clustering

\begin{tabular}{|l|l|l|}
\hline \multicolumn{1}{|c|}{ Layer } & \multicolumn{2}{|c|}{ Element } \\
\hline Package software & Server & $\begin{array}{l}\text { Virtualization, Multi-tenancy, Quality, Data isolation, SaaS placement, Enterprise application, } \\
\text { Document-oriented database, }\end{array}$ \\
\cline { 2 - 3 } & Data & $\begin{array}{l}\text { Dynamic tracking usage of virtualized environment, Mobile software app, Management module, limited } \\
\text { center }\end{array}$ \\
\cline { 2 - 3 } & Code & $\begin{array}{l}\text { Centre, Base, Reference architecture, Multi-layer fuzzy cognitive maps, Dynamic data, Modeling } \\
\text { methodologies, Model integrators, Digital map, Database object, Variables maps, Computer } \\
\text { documentation }\end{array}$ \\
\hline $\begin{array}{l}\text { Operation system } \\
\text { application stack }\end{array}$ & Server & $\begin{array}{l}\text { Middleware, Run time, API, Layer module, SaaS deployment, Instantiated resources, Table creation, } \\
\text { Claim object, Feature molding, High performance computing, Software recommendation, Virtual } \\
\text { machine, Radio frequency identification, Digital campus, Video mixing, Generic algorithms, Hills } \\
\text { climbing, Dynamic quality attributes, Learning automata }\end{array}$ \\
\hline \multirow{5}{*}{ Other } & Data & Centre, Base \\
\cline { 2 - 3 } & Code & Middleware, Run time, API, Video mixing \\
\cline { 2 - 3 } & Server & Virtualization, Semantic web \\
\cline { 2 - 3 } & Storage & Cloud services, Hybrid cloud, Cloud tech \\
\cline { 2 - 3 } & Network & $\begin{array}{l}\text { Virtual network embedding, Network effect, Authentication server, Service unite, Wireless sensor } \\
\text { network, Service discovery }\end{array}$ \\
\cline { 2 - 3 } & Security & $\begin{array}{l}\text { Identity management, Service access authorization request, Code identifier system, Method for } \\
\text { controlling, Privacy protection, Protection, Traffic cloud, Request access token, Data security, Attribute } \\
\text { based access control, Resources sharing }\end{array}$ \\
\cline { 2 - 3 } & Usability & Technology acceptance model, Adoption, Sweepstakes opportunity to player \\
\hline Source: authors. & \multicolumn{2}{|l}{} \\
\hline
\end{tabular}


Table 5. Technical Topics of Scientific Papers in 2014-2018

\begin{tabular}{|c|c|c|c|c|c|}
\hline Domain & 2014 & 2015 & 2016 & 2017 & 2018 \\
\hline Cloud Service & Cloud computing (7) & $\begin{array}{l}\text { Cloud computing (8); } \\
\text { SaaS (1) }\end{array}$ & $\begin{array}{l}\text { Cloud } \\
\text { computing (7); } \\
\text { SaaS (1) }\end{array}$ & $\begin{array}{l}\text { Cloud computing (5); } \\
\text { IaaS (1); SaaS (1) }\end{array}$ & $\begin{array}{l}\text { Cloud } \\
\text { computing (5); }\end{array}$ \\
\hline $\begin{array}{l}\text { Package } \\
\text { Software - Server }\end{array}$ & Multi-Tenancy (3) & Quality (2) & $\begin{array}{l}\text { Data Isolation } \\
\text { (1); Multi- } \\
\text { Tenancy (2) }\end{array}$ & Multi-Tenancy (4) & SaaS Placement \\
\hline $\begin{array}{l}\text { Package } \\
\text { Software - code }\end{array}$ & Reference Architecture & $\begin{array}{l}\text { Reference Architecture; } \\
\text { Multi-Layer Fuzzy } \\
\text { Cognitive Maps (1) }\end{array}$ & - & Dynamic Data & $\begin{array}{l}\text { Modeling } \\
\text { Methodologies }\end{array}$ \\
\hline $\begin{array}{l}\text { Package } \\
\text { Software - data }\end{array}$ & $\begin{array}{l}\text { Feature Modeling (3); } \\
\text { High Performance } \\
\text { Computing (2); Software } \\
\text { Recommendation; Virtual } \\
\text { Machine; Radio Frequency } \\
\text { Identification, Digital } \\
\text { Campus }\end{array}$ & $\begin{array}{l}\text { Video Mixing; Virtual } \\
\text { Machine (2); Genetic } \\
\text { Algorithms (1); Genetic } \\
\text { Algorithms (1); Hill } \\
\text { Climbing }\end{array}$ & $\begin{array}{l}\text { Virtual Machine } \\
\text { (2); Dynamic } \\
\text { Quality } \\
\text { Attributes; } \\
\text { Learning } \\
\text { Automata (1) }\end{array}$ & - & - \\
\hline $\begin{array}{l}\text { Operation Sys. } \\
\text { App. Stack- } \\
\text { Server }\end{array}$ & Web Application (1) & $\begin{array}{l}\text { Social Software (1); } \\
\text { Web Services (1); Web } \\
\text { Application (1); Mobile } \\
\text { Cloud Computing; } \\
\text { Quality (2) }\end{array}$ & - & - & $\begin{array}{l}\text { Web Based } \\
\text { Services }\end{array}$ \\
\hline $\begin{array}{l}\text { Operation Sys. } \\
\text { App. Stack-Code }\end{array}$ & - & - & - & - & - \\
\hline $\begin{array}{l}\text { Operation Sys. } \\
\text { App. Stack-data }\end{array}$ & - & Video Mixing & - & - & - \\
\hline Server & Semantic Web & $\underline{-}$ & 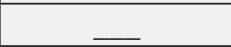 & 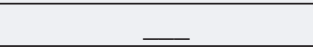 & $\ldots$ \\
\hline Storage & Cloud Service (2); Storage & 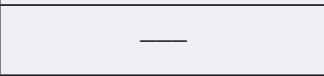 & $\begin{array}{l}\text { Cloud Library } \\
\text { Service (2) }\end{array}$ & $\begin{array}{l}\text { Storage (1); Hybrid } \\
\text { Cloud (1) }\end{array}$ & Cloud Tech (1) \\
\hline Network & $\begin{array}{l}\text { Network (2); Wireless } \\
\text { Sensor Network }\end{array}$ & Service Discovery & - & $\begin{array}{l}\text { Virtual Network } \\
\text { Embedding (1) }\end{array}$ & Network Effect \\
\hline Security & - & Security (4) & Security (1) & $\begin{array}{l}\text { Data Security (2); } \\
\text { Attribute Based Access } \\
\text { Control; Privacy } \\
\text { Protection; Resource } \\
\text { Sharing } \\
\end{array}$ & Security (2) \\
\hline Usability & - & Adoption (2) & $\begin{array}{l}\text { Technology } \\
\text { Acceptance } \\
\text { Model }\end{array}$ & - & - \\
\hline
\end{tabular}

radio frequency identification in 2014, digital campus in 2014, video mixing in 2015, genetic algorithms in 2015, hills climbing in 2015, dynamic quality attribute in 2016, and learning automata in 2016. The major technical development of the "SaaS software package" in scientific papers was multi-tenancy technology in servers and virtual machine technology in code. From the second feature of the first paper of SaaS usability, adoption appeared in 2015 and the technology acceptance model in 2016. As a result of finding major technical topics in "server, storage, network, and security", cloud services and security have a higher development level than other technological topics.

\section{Analysis of the Path of the Technological Evolution Based on Patents}

We obtained the technical topics from the patents based on the classification of the clustering results from 2014-2018 as shown in Table 6 with the help of our domain experts and the two senior researchers of our expert panel. In Table 6, the technical topics' appearance years are shown. The number between the brackets represents the number of documents containing the topic.

As shown in Table 6, the obtained technical topics in the patents related to software as a service technology includes; Enterprise Application, Module Integrator, Table Creation,
Claim Object, Enterprise Application, and Cloud Service in 2014. In 2015, the new technical topics that appeared for the first time are Document Oriented Database, Account Provisioning Component, Digital Map, Instantiated Resources, Mobile Application, and Sweepstakes Opportunity to Player. In 2016, many new technical topics appeared for the first time, including Dynamically Tracking Usage of Virtualized Environment, Web Application, Services Access Authorization Request, Code Identifier System, and a Method for Controlling. In 2017, seven new technical topics appeared for the first time, Variable Term, SaaS Deployment, Traffic Cloud, Layer Module, SaaS Deployment, Mobile Software Application, and Database Object. In 2018, six new technical topics appeared: Authentication Server, Service Unite, Request Access Token, Computer Documentation, Management Module, and Limited Content.

Table 6 shows the applied research related to SaaS technology between 2014 and 2018. In Table 6, the package software section showed a high growth percentage in 2017. The operation system application stack showed a high growth percentage in 2016. Security also demonstrated high growth in 2016. A high growth rate means the high exception of forecasting development for the technological topics package software. The operation system application stack, server, network, security, storage, and usability have great development potential, which also 
Table 6. Technical Topics of Patents in 2014-2018

\begin{tabular}{|c|c|c|c|c|c|}
\hline Tech. Topic & 2014 & 2015 & 2016 & 2017 & 2018 \\
\hline Cloud Service & 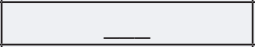 & $\ldots$ & $\ldots$ & & $\ldots$ \\
\hline \multirow[t]{3}{*}{$\begin{array}{l}\text { Package } \\
\text { Software }\end{array}$} & $\begin{array}{l}\text { Enterprise } \\
\text { Application (14) }\end{array}$ & $\begin{array}{l}\text { Document Oriented } \\
\text { Database (2); Account } \\
\text { Providing Component } \\
120(2)\end{array}$ & $\begin{array}{l}\text { Enterprise Application } \\
\text { Stores Interface (6); } \\
\text { Dynamic Tracking } \\
\text { Usage of Virtualized } \\
\text { Environment (2) }\end{array}$ & $\begin{array}{l}\text { Mobile Software } \\
\text { Application (9) }\end{array}$ & $\begin{array}{l}\text { Management Module } \\
\text { (8); Limited Content } \\
\text { (8); Enterprise } \\
\text { Resource Management } \\
\text { Application (7) } \\
\end{array}$ \\
\hline & $\begin{array}{l}\text { Module Integrator } \\
\text { (6) }\end{array}$ & Digital Map (3) & - & $\begin{array}{l}\text { Database Object } \\
\text { (3); Digital Map } \\
\text { (2); Variable } \\
\text { Term (2) }\end{array}$ & $\begin{array}{l}\text { Computer } \\
\text { Documentation (7) }\end{array}$ \\
\hline & $\begin{array}{l}\text { Table Creation } \\
\text { (2); Claim Object } \\
\text { (7) }\end{array}$ & Instantiated Resources (5) & - & $\begin{array}{l}\text { Layer Module } \\
\text { (6); SaaS } \\
\text { Deployment (9) }\end{array}$ & - \\
\hline \multirow{3}{*}{$\begin{array}{l}\text { Operation } \\
\text { System } \\
\text { Application } \\
\text { Stack }\end{array}$} & $\begin{array}{l}\text { Enterprise } \\
\text { Application (14) }\end{array}$ & Mobile Application (8) & $\begin{array}{l}\text { Enterprise Application } \\
\text { Store Interface (6); Web } \\
\text { Application (7) }\end{array}$ & $\begin{array}{l}\text { Mobile Software } \\
\text { Application (9) }\end{array}$ & SaaS Layer (9) \\
\hline & $\bar{C}$ & $\bar{C}$ & $\ldots$ & Variable Term (2) & $\overline{\bar{L}}$ \\
\hline & - & - & - & $\begin{array}{l}\text { SaaS } \\
\text { Deployment (9) }\end{array}$ & - \\
\hline Other: Server & $\ldots$ & $\ldots$ & - & - & - \\
\hline Storage & Cloud Service (10) & $\bar{\tau}$ & $\bar{C}$ & $\bar{C}$ & $\ldots$ \\
\hline Network & - & - & - & - & $\begin{array}{l}\text { Authentication Server } \\
\text { (11); Service Unite (10) }\end{array}$ \\
\hline Security & - & - & $\begin{array}{l}\text { Service Access } \\
\text { Authorization Request } \\
\text { (5); Code Identifier } \\
\text { System (3); Method for } \\
\text { controlling (14) }\end{array}$ & Traffic Cloud & $\begin{array}{l}\text { Request Access Token } \\
\text { (5) }\end{array}$ \\
\hline Usability & 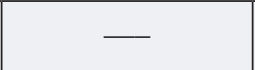 & $\begin{array}{l}\text { Sweepstakes Opportunity } \\
\text { to Player (2) }\end{array}$ & - & - & - \\
\hline
\end{tabular}

means that these technical topics may be the applied research focuses related to SaaS technology in the future.

We generated the evolution map according to the clustering topics that have been selected from the scientific database and experts' experience in order to understand the detailed evolutionary path of SaaS technology. Our two domain experts generated the SaaS evolution map based on its hierarchical structure and the annual technical topics shown in Table 6. We categorized the topics into appropriate layers of SaaS and placed them on the evolutionary map based on scientific patents in Table 6. As shown in Table 6, the vertical axis represents the Package Software layer, Operation System Application stack layer, and others include the Server, Storage, Network and Security, and Usability layer obtained from the hierarchical structure's first layer. The horizontal axis represents the year.

According to Table 6, in package of software, there are many technical topics in the scientific patents related to SaaS technology such as the following. Enterprise Application technology appeared in 2014. In 2015, the Document Oriented Database and Account Provisioning Component appeared. The Enterprise Application Store Interface and Dynamically Tracking Usage of Virtualized Environment appeared in 2016. In 2017, Mobile Software Application appeared in SaaS scientific patents. Management Module, Limited Content, and Enterprise Resource Management Application appeared in 2018. From the feature of the first layer of SaaS "Software package" there is data showing that the Module Integrator appeared in 2014 and the Digital Map appeared in both 2015 and 2017. Also, there is one more technology in SaaS patents: data appeared in 2017 concerning the Database Object. In 2018, Computer Documentation appeared as a technology in the software package in patents of SaaS. Finally, the software package also includes Table Creation and Claim Object, which appeared in 2014 and Instantiated Resources in 2015. Layer Module and SaaS Deployment appeared as a technology in the code of the software package in 2017.The second feature of the first layer of SaaS "operation systems and application stack" includes server, data, and code. In server of operation systems and application stack, Enterprise Application appeared in 2014. Mobile Application appeared in patents in both 2015 and 2017. Enterprise Application Store Interface and Web Application appeared in 2016. In 2018, SaaS Layer appeared in patents. In the data of the operation systems and application stack, Variable Term appeared in patents in 2017 as did SaaS Deployment.

The third feature of the first layer of SaaS "Other" includes storage, network, security, and usability. In the SaaS patents, Cloud Service was the only technical topic that appeared in 2014. The Sweepstakes Opportunity to Player topic appeared in 2015, which encourages companies to pay more attention to this area of online games and create competitive software for customers. In scientific papers concerning SaaS storage, Services Access Authorization Request, Code Identifier System, and Method for Controlling appeared in 2016. Traffic Cloud appeared in 2017. In 2018, Authentication Server and Service Unite appeared in patents concerning the network. Also, Request Access Token appeared in patents for SaaS in security.

\section{Analyzing the Gaps between Science and Technology for Forecasting Technology Trends}

In Table 7, the dissimilar evolutionary paths of SaaS technology based on scientific papers and patents using text mining are shown. These tables describe the different progression be- 
Table 7. Comparison of Technology Trends Analysis Based on Scientific Papers and Patents

\begin{tabular}{|l|c|c|c|}
\hline \multirow{2}{*}{\multicolumn{1}{|c|}{ Topics }} & \multicolumn{2}{c|}{$\begin{array}{c}\text { Time of topics } \\
\text { appearance }\end{array}$} & \multirow{2}{*}{ Time leg } \\
\cline { 2 - 3 } & in papers & in patents & \\
\hline Web application & 2014 & 2016 & 2 \\
\hline Cloud Service & 2014 & 2014 & 0 \\
\hline Dynamic Data & 2016 & 2016 & 0 \\
\hline Mobile Application & 2015 & 2015 & 0 \\
\hline Identifier System & 2015 & 2016 & 1 \\
\hline Hybrid Cloud & 2017 & & \\
\hline Virtual Networking & 2017 & & \\
\hline $\begin{array}{l}\text { Modeling } \\
\text { Methodologies }\end{array}$ & 2018 & - & \\
\hline Source: authors. & & & \\
\hline
\end{tabular}

tween scientific papers and patents. Understanding the connection between technology and science is important for personal users, administrators, policymakers, and entrepreneurs focusing on the changes of technology [Shibata et al., 2010]. They suggested that in the effective technical studies area, topics that appear in papers but not in patents are taken into account as technological opportunities. Technological opportunities allow for determining technological evolution [Olsson, 2005]; consequently, recognizing technological opportunities for forecasting technology development trends is critical. As we see in Table 7, the paper provides a comparative analysis of the first appearance of the technical topics in the papers and in patents database. Authors efficiently recognized the technological opportunities in the area of SaaS technology, which is important to understanding the technology's development trends clearly by comparing the time difference between the first appearance of the technical topics in scientific papers and in patents.

As we see in Figure 3, in 2014 clustering technical topics such as cloud services and web application showed up in the scientific papers, however only cloud service appeared in that year's patents. Therefore, after 2014, the web application can be taken into account as a technological opportunity. The web application showed up in 2016 in the patents. The result validated the predicted technological opportunity.

In Table 7 and Figure 3, in 2015, new technical topics like mobile application and identifier system showed up in scientific papers, but only mobile applications appeared in that year's patents. Therefore, after 2015, the identifier system can be considered a technological opportunity. In the patents, the dynamic data, mobile application, and identifier system appeared in 2016, and only dynamic data appeared in scientific papers in the same year. The validation of these results proved the forecasted technological opportunities. Consequently, it is possible to identify technological opportunities according to the time lag between the technical topics that first appeared in patents and papers. In 2017, other technical topics only appeared in papers, such as hybrid cloud and virtual networking. In 2018, new technical topics appeared only in papers such as modeling methodologies. As there are no patents corresponding to the hybrid cloud, virtual networking, and the modeling methodologies before 2018, these three technical topics could become technological opportunities after 2018.

In Table 7 and Figure 3, the high growth rate in 2014 to 2015 in the scientific database concerns web application. However, in patents, the web applications have a high growth rate in 2015 2017. In 2015, the cloud service in papers has a high growth rate, but in patents, the cloud service has a high growth rate only in 2016. In 2015, mobile applications in the scientific database had a higher growth rate while in the patents, the mobile application demonstrated a higher growth rate as a topic in 2015. The virtual machine in the papers and patents had a slow growth rate in 2014, 2015, and 2016. Also, the multitenancy in the papers and patents had a slow growth rate in 2014, 2016, and 2017. Regarding the outcomes, we see that the technical topics with high growth rates first appeared in scientific data. Then, in the patents database, topics followed the same growth trends. For that, we can forecast the changes of technical topics' growth in patents based upon the technological changes in scientific papers.

From these analyses, by evaluating the correlation between the technical topics in the patents and scientific papers, we are able to forecast the changes in technological development. Also, from Table 7 and Figure 3, the authors analyzed the gaps and found the technological development trends.

Also, the high growth rate of technical topics is worth considering when it comes to predicting potential development changes of technology. Knowing the high growth rate of certain technical topics helps to bring the researchers' attention to future studies [Bildosola et al., 2017]. In this study, we have obtained topics from scientific papers and patents. Then, we have compared the growth rates of these technical topics. The aim of these processes is to discover the potential growth trends of these technical topics. The topics in Table 7 are the top topics with high growth rates according to the percentage increase of these topics from 2014 to 2018. There are many new topics that first appeared in 2014 but, again, only those with the highest growth rates were considered. Table 8 shows the annual five technical topics with the highest growth rates. These topics are presented in scientific papers and patents. The number in brackets show the growth rate of the topic with respect to the former year.

The outcomes of the first appearance of the technical topics in papers and patents and the growth rates of those topics help one have a better understanding of the gaps between science and technology and therefore better forecast technology

Table 8. Rapidly Growing Topics Covered in Papers and Patents from 2014 to 2018

\begin{tabular}{|l|c|c|c|c|}
\hline \multicolumn{1}{|c|}{ Topics } & $\mathbf{2 0 1 4}$ & $\mathbf{2 0 1 5}$ & $\mathbf{2 0 1 6}$ & $\mathbf{2 0 1 7}$ \\
\hline Cloud Service & Cloud Computing (7) & Cloud Computing (8) & Cloud Computing (7) & Cloud computing (5) \\
\hline Package Software - Server & Multi-Tenancy (3) & & Multi-Tenancy (2) & \\
\hline Package Software & Virtual Machine & Virtual Machine (2) & Virtual Machine (2) & - \\
\hline $\begin{array}{l}\text { Operation System Application } \\
\text { Stack }\end{array}$ & $\begin{array}{c}\text { Web Application (1); } \\
\text { Mobile Application (8) }\end{array}$ & Web Application (1) & Web Application (7) & $\begin{array}{c}\text { Mobile Software } \\
\text { Application (9) }\end{array}$ \\
\hline
\end{tabular}

Not: The number in brackets presents the growth rate of the topic with respect to the former year.

Source: authors. 

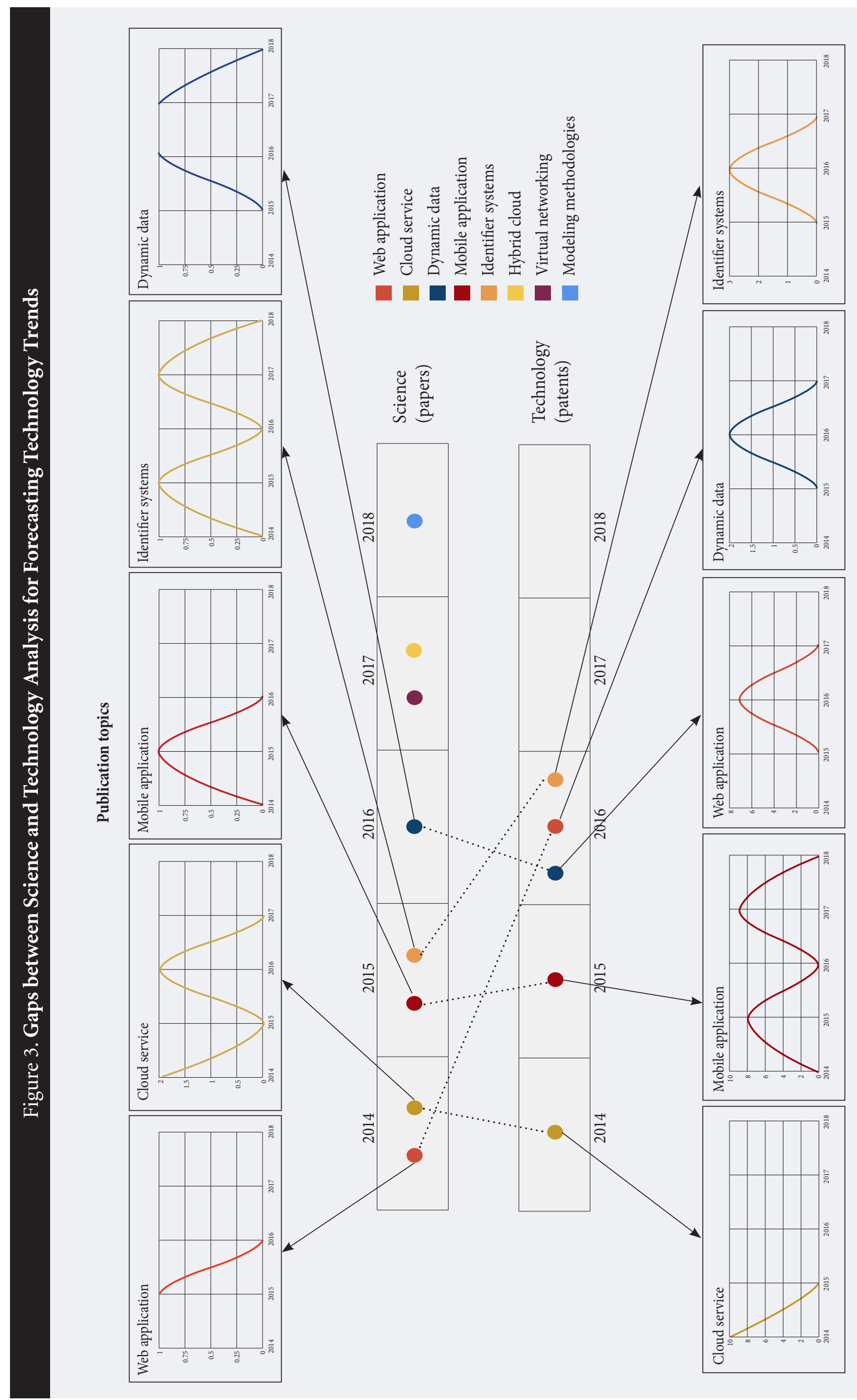

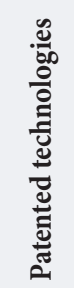


trends based on the gaps analysis. By using Table 7, along with Figure 3, we can analyze the gaps between science and technology, and the results are as follows:

(1) Virtual networking first showed up in scientific papers in 2017. While it has not yet shown up in patents, we can forecast that after 2017, virtual networking has high growth potential in patents.

(2) The hybrid cloud first showed up in scientific papers in 2017. While it has not appeared in patents, we can forecast that after 2017, the hybrid cloud will show up in patents with high growth potential.

(3) The modeling methodologies first appeared in scientific papers in 2018. While it has not yet appeared in patents, we can forecast that after 2018, the modeling methodologies will have high growth potential in patents.

(4) The mobile application first showed up in scientific papers in 2014 and presented a higher growth rate in the period of 2015 to 2017 . However, the mobile application only appeared in patents in 2016. We can forecast that after 2016 the mobile application will have high growth potential in patents.

(5) The web application first showed up in scientific papers in 2014 and presented a high growth rate in 2014 and in 2016. However, the web application only appeared in patents in 2016. We can forecast that after 2016 the web application will have high growth potential in patents.

We predict that mobile application, web application, hybrid cloud technology, virtual networking, and modeling methodologies will be the future development trends of software as a service technology based on the results of analyzing the gaps between science and technology.

\section{Discussion}

This paper adopts a framework developed by [Li et al., 2019] to study technology trends using scientific papers and patents as data resources. This framework is based on identifying a patent and paper dataset and analyzing the gap between the findings, which shows the growth rates in selected technologies. Utilizing text mining to cluster topics shown in scientific papers and expert judgement to identify the technological evolutionary path, we were able to identify trends. Consistent with the original paper, we found that the gap analysis of the first appearance between scientific papers and patents does confirm the development trends. Topics that earlier appeared in scientific papers then appeared several years later in patents suggest a trend. This trend can be used to predict future patents based on topics in the literature.

The evolutionary path of SaaS in e-commerce was constructed in an attempt to better understand emerging and future trends. Our findings reveal five trends in the technology: 1) Virtual networking first appeared in scientific papers in 2017 and we predict that it will appear in patents after 2017 with high growth potential. 2) The hybrid cloud also first appeared in scientific papers in 2017, and again we predict that it will appear in patents after 2017 with high growth potential. 3) Modeling methodologies first appeared in scientific papers in 2018, it has not appeared in patents yet, thus we forecast that after 2018, it will have high growth. 4) Mobile application first appeared in scientific papers in 2014 and showed a higher growth rate in the period between 2015 and 2017. However, it appeared in patents in 2016, we can predict that it will have high growth potential in patents after 2016. 5) In 2014, the web application first showed up in scientific papers and also presented a high growth rate in both 2014 and in 2016. However, it appeared in patents in 2016. We can forecast that after 2016, the web application will have high growth possibility in patents.

\section{Conclusions}

According to the results, this paper suggests a framework that employs scientific papers and patents as sources of data and merges text mining with expert knowledge and a judgment method to forecast the technological changes of SaaS technology by recognizing the gaps between science and technology. E-commerce marketing is complex. It needs many skills such as data extraction, transformation, and manipulation. The text mining and expert judgment methods were used for analyzing the technical topics appearing in scientific papers and patents. We applied gaps analysis between science and technology to forecast the technological development changes. SaaS technology was selected as a case study, through which the proposed framework was proven to be effective. The SaaS technology forecasting methodology in this paper focuses on the evolution and future trends of technology research and development.

It is possible to say that traditional information systems are now evolving into online information systems. The main reason for this evolution is the developments in cloud computing technologies. It is possible to attribute the cost advantage of cloud computing technologies to many enterprises without allocating scale. One can say that the three main components of cloud computing technology, service, platform, and infrastructure, consist of software as a service. In this respect, the model drawn in Figure 2 has the potential to be a guide in many sectors, especially in e-commerce. On the other hand, the use of a licensing model based on subscription triggers a change in permanent licensing models. When analyzed by years, the change in technologies is clearly seen. The product range that has evolved toward mobile technologies has put pressure on information storage and storage technologies and has led to a search for new methods especially in the development of database systems.

This paper has limitations that can be addressed in future research. The method was only applied to one area and there were a limited number of observations upon which to build a solid case. In addition, the conclusions were made based on visual observations. The approach can be significantly improved with machine learning techniques enabling the analysis of a much larger dataset and more robust results.

Furthermore, we observed that using scientific papers and patents to predict technological trends also has several limitations. First, important information may be missing because of publishing lag times [Huang et al., 2014]. For future work, additional case studies might look into the time lag of the technical topics' appearances in scientific papers and patents, which could be an opportunity for forecasting technology trends. Second, some science and technology developments are published but not all of them, and some of the records are valuable [Porter, Detampel, 1995]. Therefore, a scenario-planning technique combined with text mining may be valuable in further research to forecast the changes of the technology and model the future development of that technology. Bias in the presented approach can also be addressed by working with an expert panel and automating the process with machine learning techniques.

The article was prepared within the framework of the Basic Research Program of the National Research University Higher School of Economics. 


\section{References}

Angelou K., Maragakis M., Argyrakis P. (2019) A structural analysis of the patent citation network by the k-shell decomposition method. Physica A: Statistical Mechanics and Its Applications, 521, 476-483. https://doi.org/10.1016/j.physa.2019.01.063

Bengisu M., Nekhili R. (2006) Forecasting emerging technologies with the aid of science and technology databases. Technological Forecasting and Social Change, 73(7), 835-844. https://doi.org/10.1016/j.techfore.2005.09.001

Bildosola I., Río-Bélver R.M., Garechana G., Cilleruelo E. (2017) TeknoRoadmap: An approach for depicting emerging technologies. Technological Forecasting and Social Change, 117, 25-37. https://doi.org/10.1016/j.techfore.2017.01.015

Boyack K.W., van Eck N.J., Colavizza G., Waltman L. (2018) Characterizing in-text citations in scientific articles: A large-scale analysis. Journal of Informetrics, 12(1), 59-73. https://doi.org/10.1016/j.joi.2017.11.005

Chen C.M., Ibekwe-SanJuan F., Hou J. H. (2010) The Structure and Dynamics of Cocitation Clusters: A Multiple-Perspective Cocitation Analysis. Journal of the American Society for Information Science and Technology, 61(7), 1386-1409. https://doi.org/10.1002/asi.21309

Chen C. (1998) Bridging the gap: The use of pathfinder networks in visual navigation. Journal of Visual Languages \& Computing, 9(3), 267-286. https://doi.org/10.1006/jvlc.1998.0083

Chen H., Zhang G., Zhu D., Lu J. (2017) Topic-based technological forecasting based on patent data: A case study of Australian patents from 2000 to 2014. Technological Forecasting and Social Change, 119(7), 39-52. https://doi.org/10.1016/j.techfore.2017.03.009

Chen W., Shen B.J., Qi Z.W. (2011) Research and implementation of business logic customization framework for SaaS applications. Jisuanji Yingyong Yanjiu, 28(1), 155-158.

Choi S., Park H., Kang D., Lee J.Y., Kim K. (2012) An SAO-based text mining approach to building a technology tree for technology planning. Expert Systems with Applications, 39(13), 11443-11455. https://doi.org/10.1016/j.eswa.2012.04.014

Christensen C.M. (1997) The innovator's dilemma: When new technologies cause great firms to fail, Boston, MA: Harvard Business School Press.

Coates V., Farooque M., Klavans R., Lapid K., Linstone H.A., Pistorius C., Porter A.L. (2001) On the Future of Technological Forecasting. Technological Forecasting and Social Change, 67(1), 1-17. https://doi.org/10.1016/S0040-1625(00)00122-0

Cusumano M.A. (2008) The changing software business: Moving from products to services. Computer, 41(1), 20-27. https://doi. ieeecomputersociety.org/10.1109/MC.2008.29

Elfatatry A., Layzell P. (2002) Software as a service: A negotiation perspective. In: Proceedings of the 26th Annual International Conference on Computer Software and Applications, 26-29 August 2002, Oxford, UK (ed. D.C. Martin), Piscataway, NJ: IEEE, pp. 501-506. https://ieeexplore. ieee.org/document/1045054, accessed 06.04.2021.

García-Lillo F., Claver-Cortés E., Marco-Lajara B., Úbeda-García M. (2019) Identifying the 'knowledge base' or 'intellectual structure' of research on international business, 2000-2015: A citation/co-citation analysis of JIBS. International Business Review, 28(4), 713-726. https:// doi.org/10.1016/j.ibusrev.2019.02.001

Ghazinoory S., Ameri F., Farnoodi S. (2013) An application of the text mining approach to select technology centers of excellence. Technological Forecasting and Social Change, 80(5), 918-931. https://doi.org/10.1016/j.techfore.2012.09.001

Graham R.L., Hell P. (1985) On the history of the minimum spanning tree problem. Annals of the History of Computing, 7(1), 43-57. https:// doi.org/10.1109/MAHC.1985.10011

Hasner C., de Lima A.A., Winter E. (2019) Technology advances in sugarcane propagation: A patent citation study. World Patent Information, 56, 9-16. https://doi.org/10.1016/j.wpi.2018.09.001

Huang L., Zhang Y., Guo Y., Zhu D.H., Porter A.L. (2014) Four-dimensional Science and Technology Planning: A New Approach Based on Bibliometrics and Technology Roadmapping. Technological Forecasting and Social Change, 81(1), 39-48. https://doi.org/10.1016/j. techfore.2012.09.010

Huang Y., Porter A.L., Zhang Y., Lian X., Guo Y. (2018) An assessment of technology forecasting: Revisiting earlier analyses on dye-sensitized solar cells (DSSCs). Technological Forecasting and Social Change, 146, 831-843. https://doi.org/10.1016/j.techfore.2018.10.031

Kim G., Bae J. (2017) A novel approach to forecast promising technology through patent analysis. Technological Forecasting and Social Change, 117, 228-237. https://doi.org/10.1016/j.techfore.2016.11.023

Kim H.J., Jeong Y.K., Song M. (2016) Content- and proximity-based author co-citation analysis using citation sentences. Journal of Informetrics, 10(4), 954-966. https://doi.org/10.1016/j.joi.2016.07.007

Kose T., Sakata I. (2018) Identifying technology convergence in the field of robotics research. Technological Forecasting and Social Change. https://doi.org/10.1016/j.techfore.2018.09.005

Laplante P.A., Zhang J., Voas J. (2008) What's in a Name? Distinguishing between SaaS and SOA. IT Professional, 10(3), 46-50. https://doi. ieeecomputersociety.org/10.1109/MITP.2008.60

Lee H., Lee S., Yoon B. (2011) Technology clustering based on evolutionary patterns: The case of information and communications technologies. Technological Forecasting and Social Change, 78(6), 953-967. https://doi.org/10.1016/j.techfore.2011.02.002

Li X., Xie Q., Daim T., Huang L. (2019) Forecasting technology trends using text mining of the gaps between science and technology: The case of perovskite solar cell technology. Technological Forecasting and Social Change. https://doi.org/10.1016/j.techfore.2019.01.012

Ma D. (2007) The business model of "Software-as-a-Service". In: Proceedings of the IEEE International Conference on Services Computing (SCC 2007), Salt Lake City, UT, 9-13 July 2007, Hoboken, NJ: IEEE, pp. 701-702. http://doi.ieeecomputersociety.org/10.1109/SCC.2007.118.

Madani F., Weber C. (2016) The evolution of patent mining: Applying bibliometrics analysis and keyword network analysis. World Patent Information, 46, 32-48. https://doi.org/10.1016/j.wpi.2016.05.008

Olsson O. (2005) Technological opportunity and growth. Journal of Economic Growth, 10(1), 31-53. https://doi.org/10.1007/s10887-005-1112-4

Park C., Yong T. (2017) Prospect of Korean nuclear policy change through text mining. Energy Procedia, 128, 72-78. https://doi.org/10.1016/j. egypro.2017.09.017

Porter A.L., Cunningham S.W. (2004) Tech Mining: Exploiting New Technologies for Competitive Advantage, Hoboken, NJ: Wiley.

Porter A.-L., Detampel M.J. (1995) Technology opportunities analysis. Technological Forecasting and Social Change, 49(3), 237-255. https://doi. org/10.1016/0040-1625(95)00022-3

Rezaeian M., Montazeri H., Loonen R.C.G.M. (2017) Science foresight using life-cycle analysis, text mining and clustering: A case study on natural ventilation. Technological Forecasting and Social Change, 118, 270-280. https://doi.org/10.1016/j.techfore.2017.02.027

Rongying Z., Limin X. (2010) The Knowledge Map of the Evolution and Research Frontiers of the Bibliometrics. Journal of Library Science in China, 5, 60-68. https://en.cnki.com.cn/Article_en/CJFDTotal-ZGTS201005007.htm, accessed 06.04.2021.

Shibata N., Kajikawa Y., Sakata I. (2010) Extracting the commercialization gap between science and technology - Case study of a solar cell. Technological Forecasting and Social Change, 77(7), 1147-1155. https://doi.org/10.1016/j.techfore.2010.03.008

SIIA (2001) Software as a Serice: Strategic Backgrounder. Washington, D.C.: Software \& Information Industry Association.

Teufel S., Siddharthan A., Tidhar D. (2009) An annotation scheme for citation function. In: SigDIAL '06: Proceedings of the 7th SIGdial Workshop on Discourse and Dialogue (eds. J. Alexandersson, A. Knott), Stroudsburg, PA: Association for Computational Linguistics, pp. 80-87. http:// dl.acm.org/citation.cfm?id=1654595.1654612, accessed 06.04.2021.

Wang M.-Y., Fang S.-C., Chang Y.-H. (2015) Exploring technological opportunities by mining the gaps between science and technology: Microalgal biofuels. Technological Forecasting and Social Change, 92, 182-195. https://doi.org/10.1016/j.techfore.2014.07.008

Yoon B., Park I., Coh B. (2014) Exploring technological opportunities by linking technology and products: Application of morphology analysis and text mining. Technological Forecasting and Social Change, 86, 287-303. https://doi.org/10.1016/j.techfore.2013.10.013

Yoon B., Park Y. (2005) A systematic approach for identifying technology opportunities: keyword-based morphology analysis. Technological Forecasting and Social Change, 72 (2), 145-160. https://doi.org/10.1016/j.techfore.2004.08.011 